\title{
Referaat
}

\section{Web- or paper-based portfolios: is there a difference?}

Driessen EW, Muijtjens AMM, van Tartwijk T, van der Vleuten CPM. Webor paper-based portfolios: is there a difference? Med Educ 2007:41:1067-1073.

Beïnvloedt het gebruikte medium (elektronisch of papier) de kwaliteit van het portfolio? Dit is door Driessen et al. onderzocht in een experimenteel onderzoek waarin 45 elektronische en 47 papieren portfolio's van dezelfde onderwijseenheid zijn vergeleken op kwaliteit, motivatie van de studenten en op gebruikersvriendelijkheid.

Een experiment in een onderwijssituatie is vaak lastig te realiseren. Dit fraai opgezette, gecontroleerde onderzoek laat zien dat het wel degelijk mogelijk is. Het onderzoek is verricht aan de hand van portfolio's van eerstejaars studenten geneeskunde in Maastricht. Deze portfolio's zijn geanalyseerd met behulp van een scoringsinstrument. Daarnaast zijn er interviews gehouden met portfoliobegeleiders en is er een vragenlijst afgenomen onder studenten.

Aanleiding voor het onderzoek was het gebrek aan bewijs voor uitspraken van zowel voor- als tegenstanders van het elektronische portfolio. Tegenstanders zijn vaak huiverig omdat ze vrezen dat de invoering van een elektronisch portfolio tot oppervlakkiger reflecties zal leiden. Voorstanders verwachten juist dat de kwaliteit van elektronische portfolio's zal verbeteren door het gebruik van extra technische mogelijkheden enerzijds en anderzijds omdat studenten gedwongen worden beknopter en gestructureerder te schrijven. Andere vaak genoemde voordelen zijn de gebruikersvriendelijkheid en de verwachting dat de motivatie van studenten die met een elektronisch portfolio werken zal toenemen.

Uit het onderzoek blijkt dat er wat betreft de kwaliteit geen significant verschil is tussen de papieren en elektronische portfolio's. Het hierboven genoemde nadeel wordt niet aangetoond en de veronderstelde voordelen worden weliswaar niet door het onderzoek bevestigd maar zeker niet verworpen. Wel komt naar voren dat de motivatie van de studenten met een elektronisch portfolio groter is. $\mathrm{Ze}$ bleken significant meer tijd te besteden aan het samenstellen van het elektronische portfolio. De grotere gebruikersvriendelijkheid werd vooral onderstreept door de begeleiders. Zij waarderen het zoekgemak en de toegankelijkheid vanaf verschillende plaatsen. De studenten zelf ervoeren deze verschillen niet maar zagen wel de voordelen voor de begeleiders. Deze bevindingen deden de onderzoeker tot slot veronderstellen dat de invoering van elektronische portfolio's de acceptatie van portfolio-onderwijs zal doen vergroten.

Zoals hierboven opgemerkt is het een mooi gecontroleerd onderzoek, maar naar mijn mening zijn er ook enkele kanttekeningen te plaatsen. Het is een 'single-site' onderzoek. Het gaat om de omzetting van het (unieke) papieren portfolio in Maastricht naar het elektronische portfolio in Maastricht. In het (medisch) onderwijs is er echter, wat betreft doel, onderwijs en 
inhoud, een grote variatie aan portfoliogebruik. Daarnaast zijn er inmiddels vele soorten elektronische portfoliosystemen. Denk daarbij aan de aanwezigheid van vele aanbieders op de verschillende onderwijscongressen. De onderzoekers gaan niet in op de vraag in hoeverre de resultaten uit het onderzoek generaliseerbaar zijn naar andere situaties.

Een tweede kanttekening bij het onderzoek is dat het zich, met betrekking tot het onderzochte aspect kwaliteit, slechts richt op het eindproduct: het ingeleverde portfolio. Echter, één van de belangrijkste doelen van portfolio-gebruik is het stimuleren tot reflectie. Om dat doel te bereiken weten we inmiddels dat goede begeleiding en adequate feedback van cruciaal belang zijn. ${ }^{1}$ Was het in dat licht niet logischer geweest om ook aandacht te besteden aan het proces: de begeleiding en de (tussentijdse) feedback? Zeker gezien de ervaringen in Groningen waar de omzetting van het papieren portfolio naar een elektronische versie leidde tot (meer dan) een verdubbeling van de hoeveelheid van de feedback. $^{2}$
Samengevat ondersteunen de uitkomsten van het onderzoek de switch naar een elektronisch portfolio. Echter, verder onderzoek is nodig, bij voorkeur onderzoek waarin meerdere faculteiten participeren. Daarbij pleit ik ervoor om ook aandacht te besteden aan de extra mogelijkheden die het elektronische portfolio in zich lijkt te bergen ten aanzien van de begeleiding. De uitkomsten van dat onderzoek kunnen wij als ontwikkelaars en docenten goed gebruiken ter optimalisering van portfolio-gebruik in het (medisch) onderwijs.

Fransje Okker, Onderwijsinstituut, Faculteit der Medische Wetenschappen, Universitair Medisch Centrum Groningen

\section{Literatuur}

1. Driessen E, van Tartwijk J, van der Vleuten C, Wass V. Portfolios in medical education: Why do they meet with mixed success? A systematic review. Med Educ 2007:41:1224-1233.

2. Okker FC, Groothuizen MM, Dekker H. Portfolio's: van papier naar elektronisch. Abstractboek 2007 Congres Nederlandse Vereniging voor Medisch Onderwijs, pp. 217. 